\title{
The Battle between Infection and Host Immune Responses of Dengue Virus and Its Implication in Dengue Disease Pathogenesis
}

\author{
Peifang Sun ${ }^{1}$ and Tadeusz J. Kochel ${ }^{2}$ \\ ${ }^{1}$ Henry M. Jackson Foundation for the Advancement of Military Medicine, Bethesda, MD 20817, USA \\ ${ }^{2}$ Department of Viral and Rickettsial Diseases, Naval Medical Research Center, Silver Spring, MD 20910, USA \\ Correspondence should be addressed to Peifang Sun; peifang.sun@med.navy.mil
}

Received 16 November 2012; Accepted 3 January 2013

Academic Editors: J. Blanco, E. Borda, U. S. Gaipl, and M. Shimaoka

Copyright (c) 2013 P. Sun and T. J. Kochel. This is an open access article distributed under the Creative Commons Attribution License, which permits unrestricted use, distribution, and reproduction in any medium, provided the original work is properly cited.

\begin{abstract}
Dengue virus (DENV) is a mosquito-transmitted single stranded RNA virus belonging to genus Flavivirus. The virus is endemic in the tropical and subtropical countries of the world, causing diseases classified according to symptoms and severity (from mild to severe) as dengue fever, dengue hemorrhagic fever, and dengue shock syndrome. Among a variety of human cell types targeted by DENV, monocytes, macrophages, and dendritic cells are members of innate immunity, capable of mounting rapid inflammatory responses. These cells are also major antigen presenting cells, responsible for activating the adaptive immunity for long-term memory. This paper is an overview of the current understanding of the following mutually affected aspects: DENV structure, viral infectivity, cellular receptors, innate immune response, and adaptive immunity.
\end{abstract}

\section{Introduction}

Dengue virus (DENV) is an arthropod-borne single stranded RNA virus of genus Flavivirus. It is comprised of 4 closely related but antigenically distinct serotypes, DENV-1, $-2,-3$, and -4 . The virus is endemic in more than 100 tropical and subtropical countries of the world. Presently no specific therapies or vaccines are available to treat diseases or to prevent DENV transmission $[1,2]$.

Illnesses caused by DENV infection include undifferentiated fever, dengue fever (DF), dengue hemorrhagic fever (DHF), and dengue shock syndrome (DSS) [3, 4]. According to WHO's 1997 documentation, DF is clinically defined as an acute febrile illness with two or more manifestations of headache, retroorbital pain, myalgia, arthralgia, rash, and so on. Symptoms of DF can last 2-7 days. DHF are defined by the following criteria: persistent high fever, hemorrhage tendency, hemoconcentration $(>20 \%)$, and platelet counts $(<100,000)$ [5-8]. DHF is further classified into 4 grades according to the severity of bleeding and plasma leakage. DSS refers to DHF grades III and IV. In many areas, severe dengue illness cases rarely present all the above 4 criteria to be defined as DHF cases. Therefore, new guidelines for classification of dengue disease severity were published by WHO in 2009; however, the 1997 case definition is still in use. Currently DHF and DSS represent 2.5 to $40 \%$ of total hospitalized dengue cases [9-11], and children are most vulnerable [12,13].

Besides nutrition, age, and sex [14, 15], the following 3 factors, viral strain virulence, host genetics, and host immune status, are major contributors to DHF. Typically, dengue illnesses begin 5-7 days after a blood meal from an infected mosquito. Viremia in human peripheral blood peaks during the early days (first 2-3 days) of acute illness and then decline sharply. Higher viremia titers in DHF patients compared to that in DF cases were observed. In general, immune responses are essential for the resolution of DENV infection; however, as DHF is associated with secondary infections and symptoms of DHF emerge at the time when viremia is declined, DHF/DSS is thought to be consequences of immunopathology [16]. The three human cell types, monocytes, macrophages $(M \Phi)$, and dendritic cells (DCs), are permissible for DENV infection. These cells are major phagocytic cells of the innate immune system, responsible for detecting and removing invasive pathogens. 
They are also antigen presenting cells critical for the initiation, expansion, and polarization of adaptive cellular immunity. Targeting these cells by DENV may have a significant impact on immune modulation. In this paper, we summarized recent findings regarding the viral structures, host cells, and receptors, and host's innate and adaptive immune responses, for a better understanding of DHF pathogenesis.

\section{Dengue Virus Structure and Life Cycle}

The DENV particle is coated with a host cell-derived lipid bilayer. The genome of DENV is an $11 \mathrm{~kb}$-long single positivesensed RNA molecule encoding 10 viral proteins: 3 structural proteins, capsid $(\mathrm{C})$, membrane $(\mathrm{M})$, envelope $(\mathrm{E})$, and 7 nonstructural proteins (NS), NS-1, 2A, 2B, -3, -4A, -4B, and -5 . DENV enters into host cells through receptor-mediated endocytosis. The E proteins on viral surface are major players for viral attachment, endocytosis, uncoating, and fusion. The E protein contains 3 functional domains: domain I (130-185), domain II (50-130, 185-300), and domain III (300-400). Domain II contains a fusion peptide, while domain III is considered as a binding domain that binds to cellular receptors and direct DENV particles to host cell's endosomal compartments. Viral uncoating occurs in the cellular endosomal compartments in an acidic environment, releasing viral RNA into the cytoplasm. As a positive sense (messenger) RNA, protein translation is initiated immediately after virus uncoating. The genome RNA initially produces an uninterrupted polyprotein which is subsequently cleaved into individual proteins in host cell's ER lumen and cytoplasm. The cleavage of prM, E, NS1, and NS4B proceeds those of the other NS and C. Host cell proteases and viral protease NS2B-NS3 are required for viral protein cleavage. The NS3 is also a helicase, which joins NS5, the RNA-dependent RNA polymerase, to enable viral RNA replication in the so-called viral replication complexes (RCs) near the cellular membranes in cell cytoplasm. Newly synthesized E and PrM insert into the ER membrane, whereas the newly synthesized RNA associates with $\mathrm{C}$ to form nucleocapsid at the cytosolic side of the ER membrane. Through a mechanism termed "budding," the nucleocapsids join with the membrane bound PrM and $\mathrm{E}$, forming progeny viral particles in the rough ER cisternae. These viral particles are transported to the Golgi apparatus and then are carried within the secretory vesicle to cell surface for extracellular release. A Golgilocalized furin protease cleaves prM at a late stage of viral replication and the mature progeny virion secreted extracellularly contains M protein.

\section{Viral Infection}

3.1. Protein Glycosylation of DENV. During viral replication, protein translation in host cell's ER is continued with protein modification in ER and Golgi apparatus. One of the most common forms of protein modification is N-linked glycosylation, in which a high mannose core is attached to the amide nitrogen of asparagine (Asn) in a consensus sequence of Asn-X-Ser/Thr; X represents any amino acid. The protein modification initiates early in protein synthesis in ER and continues during protein transit through the ER to Golgi. In Golgi, the initially attached glycan is further modified by a complex process of trimming or remodeling, resulting in varying oligosaccharide structures. Glycosylation can promote proper protein folding required for protein functioning, affect interaction between virus and receptors, and alter antigenic structures recognized by host immune cells and antibody, thus impact viral replication and infectivity.

Currently, N-linked glycosylation has been shown to affect infection, genome replication, and progeny virion packaging of DENV [17-19]. The E protein of DENV is glycosylated at position Asn67 and Asn153 [17]. While the glycosylation site at Asn-153 of $\mathrm{E}$ is conserved in most Flaviviruses, the site at Asn-67 is unique for DENV [17]. Other glycosylation sites are located at PrM positions 7, 31, and 52 and within NS1 at positions 130 and 207 [20].

Depending on the types of receptors and types of host cells studied, the E protein glycosylation affects the viral infectivity and replication differently [17]. For mammalian cells (e.g., Vero cells, BHK cells), removing glycosylation of Asn-153 by gene mutation reduces the capability of the DENV to infect host cells, whereas removing Asn-67 neither affect infectivity nor replication of the viral genome but reduces virus progeny assembly. Therefore, it is suggested that Asn67 is important for proper folding of the newly synthesized $\mathrm{E}$ protein, virion assembly, and release of virions in mammalian cells. For mosquito cells (C6/36, a cell line derived from the larvae of Aetis albopictus), removing glycosylation at either Asn-153 or Asn-67 by gene mutation is not as crucial as for mammalian cells. Infection of C6/36 mosquito cells with either the Asn67 or Asn67/Asn153 mutants resulted in the introduction of a compensatory mutation, $\mathrm{K} 64 \mathrm{~N}$, restoring glycosylation in the area [21].

Direct evidence regarding the change of glycan compounds on Flavivirus surface that may impact viral tropism is from West Nile virus (WNV). Dendritic cell-specific intercellular adhesion molecule 3-grabbing nonintegrin (DCSIGN, CD209) and its homology liver/lymph node-specific ICAM-3 grabbing nonintegrin (L-SIGN also known as DCSIGNR or CD209L) are expressed on different cells of different tissues and organs. DC-SIGN is expressed on dendritic and macrophages under dermal and in lymphoid tissues, whereas its homolog L-SIGN is expressed on liver sinusoidal endothelial cells. Glycosylation of E protein at position Asn67 is critical for the interaction of DENV with the carbohydrate recognition domain (CRD) on the DC-SIGN molecule [17]. Different from DENV, WNV does not have N-linked glycosylation on Asn-67. While DENV is equally infectious for DC-SIGN and L-SIGN cells, WNV preferentially infects L-SIGN cells. The introduction of glycosylation at Asn67 abolished this preference and rendered WNV equally infectious to both DC-SIGN and L-SIGN cells. Studies show that mannose-rich glycans on WNV were required for its interactions with DC-SIGN, but not for L-SIGN, whereas complex glycans, particularly $\mathrm{N}$-acetylglucosamine terminated structures, were important for interaction with L-SIGN. This study suggested that the site of $N$-linked glycosylation on E protein molecule determines the types of glycans incorporated, thus controlling viral tropism for DCSIGN or L-SIGN-expressing cells. 
The glycan biosynthesis pathways do not need a genetic template. Glycan structures vary among species and are modulated by factors that can differ greatly among cell types. These factors contribute to the difficulty for us to understand the complicated nature of virus glycosylation. An evolving technology, glycan microarray, may be a powerful tool for profiling glycan molecules that are important for infectivity and immune recognition, thus helpful for vaccine and drug development.

\subsection{Receptors and Host Cells Identified In Vitro for DENV} Infection. A broad range of host cells have been documented for DENV infection in vitro. DENV can infect kidney-derived cells (Vero cells) from African green monkeys, baby hamster kidney cells (BHK cells), mosquito cells (C6/36), and more. Identified cellular receptors on these cells include laminin receptor [22] and other not fully characterized polypeptides [23]. In human, DENV infection has been found in monocytes, $\mathrm{M} \Phi, \mathrm{DCs}$, endothelial cells, and hepatocytes [24]. Cellular receptors for hepatocytes include heat shock protein (Hsp)70 and Hsp90 [25-28], GRP78 [25], and heparin-sulfate [29]. Cellular receptors for monocytes and $M \Phi$ include mannose receptor (CD205) [30], CD14-associated protein [31], CLEC-5A [32, 33], and heparin-sulfate [29], DC-SIGN (CD209) [34]. For DCs, the cellular receptors include DCSIGN [34]. Immature DCs express higher levels of DC-SIGN compared to mature DCs. Infectivity in immature and mature DCs differs significantly [34]. Among DCs, monocytes, and $M \Phi$, DCs are the most permissible cells for DENV infection [35]. The high infectivity in DCs is not only attributed to higher receptor-mediated uptake, but also due to higher genome replication and de novo viral protein production [30]. Some suggest that DC-SIGN only serves to concentrate the virus on the cell surface; the internalization of the virus depends on another molecule since the truncated DCSIGN lacking the endocytosis domain did not abolish virus replication [36].

The receptor for endothelial cells is not yet identified. The DC-SIGN homology L-SIGN [34] is thought to be the receptor for liver sinusoidal endothelial cells. For C6/36 cells, two surface proteins of 40 and $45 \mathrm{kDa}$ (a putative heat shock protein) were found to interact with DENV-4 [37, 38], and a receptor of $50 \mathrm{kDa}$ was found to bind to DENV-2, -3 , and $-4[22]$, thus suggesting that multiple proteins may be used as receptors. For Vero cells, heparin sulfate and two cell surface proteins of 74 and $44 \mathrm{kDa}$ mediate DENV binding [23]. According to these studies, the carbohydrate residues are important in virus binding to both C6/36 and Vero cells. Heparin sulfate is a glycosaminoglycan occurring in the cell membrane of most cells. It is assumed that heparin sulfate serves to concentrate viruses on the cell surface, and endocytosis of DENV may be dependent on another molecule. Infection through heparin sulfate has been reported for DENV-2 and -4 [39, 40].

3.3. Host Cells Identified In Vivo for DENV Infection. One approach that has been used to identify host cells in naturally infected humans is the histochemistry of autopsy samples from fatal dengue cases. DENV genome and immumofluorescent staining of DENV protein antigens are found mainly in phagocytic cells in lymph node, spleen, and lung [41, 42] by in situ RNA hybridization or immunofluorescent staining (e.g., NS-3). DENV infection was also found in perivascular cells in brain, in hepatocytes in liver, and in endothelial cells in spleen. In peripheral blood, DENV antigens were detected in $\mathrm{CD}_{1}{ }^{+}$monocytes [43]. These studies suggested that tissue $M \Phi$, blood monocytes, liver hepatocytes, and endothelial cells are target cells for DENV infection. Of note, DENV viremia is reported to be negative upon the time of defervescence and before the onset of DHF; therefore, the above-mentioned histochemistry studies may highlight more of a picture of late stage dengue tropism. A humanized mouse model may be useful to gain some light regarding a dynamic picture of DENV tropism [44]. This model showed that DENV first emerged (from day 1) outside the follicle-like structures (where $\mathrm{T}$ and $\mathrm{B}$ cells reside) of the spleen, and then in follicle-like structures (day 10). From day 14 to 18, DENVs were found outside the follicle areas. A similar pattern was found in bone marrow. These data suggested that non-T and non-B cells, such as DCs, $M \Phi$, and monocytes, are targeted first by DENV. Upon migration, these cells spread DENV to $\mathrm{T}$ and $\mathrm{B}$, and then infection goes on to other parts of the body, such as liver and lung.

3.4. Receptor Usage and Viral Virulence. Receptor preference is a key for tissue tropism and virulence of the virus, and so far, little is known regarding in vivo receptor usage during natural DENV infection and how it affects dengue disease severity. A few animal studies may shed some light on this aspect of research.

Adaptation of a DENV-4 isolate in DBS-FRhL-2 cells generated a variant isolate with a mutation of Glu327-Gly in E domain III. This variant virus showed increased affinity for heparin sulfate and reduced infectivity and immunogenicity in rhesus monkeys compared to the unpassaged DENV-4 [45]. Another study showed that a mouse-passaged DENV strain with reduced affinity for heparin sulfate causes severe disease in mice by establishing increased systemic viral loads $[46,47]$. A recombinant virus which showed weaker affinity for heparan sulfate had an increased serum half-life, higher systemic viral loads, and high levels of TNF- $\alpha$ in the serum of infected mice [47]. It is possible that different affinities to heparin sulfate could lead viruses to different tissues where the microenvironments or cell types hosting DENV do not support optimal DENV replication or spreading.

The role of DC-SIGN in DENV pathogenesis has been observed on genetics level. A single nucleotide polymorphism (SNP) study linked the polymorphism in the promoter region of CD209 (-336 A/G; rs4804803) with disease protection or severity [48]. The study looked at two genotypes, $\mathrm{A} / \mathrm{A}$ and $\mathrm{A} / \mathrm{G}$ of this promoter region and found a strong association between GG/AG genotypes of rs4804803 and risk of DHF, whereas the AA genotype was associated with protection against DENV infection [49]. The DCs generated in vitro from AG genotype had a higher DC-SIGN expression compared to AA genotype. However, it is puzzling that the higher DC-SIGN expression did not link to a higher level of 
infection; instead it linked to higher cytokine production. The TNF- $\alpha$, IP-10, and IL-12p40 were significantly higher in DCs from AG genotype compared to AA genotype, suggesting that the innate immunity may play a critical role in disease severity.

3.5. Infection through Antibody-Dependent Enhancement $(A D E)$. One of the major risk factors for DHF/DSS is the patient's previous exposure to DENV. Primary DENV infections usually result in noncomplicated DF and the development of both humoral and cellular immunity; both are long term and protect the host from reinfection from the same serotype. Although this antidengue immune response is cross-reactive in nature, it does not confer long-term crossprotection to other serotypes. Instead, an association of DHF with secondary infections was observed [50-52], providing the immunological basis for dengue pathogenesis.

The theory known as ADE suggests that the presence of nonneutralizing serum Abs from a previous exposure mediate an enhancement of infection to subsequent heterologous DENV infections. The process of ADE involves the binding of $\mathrm{Ab}$ to $\mathrm{DENV}$, forming Ab-DENV immune complexes (ICs), and the binding of the complexes to $\mathrm{FcR}$, resulting in an increased DENV uptake by FcR-bearing cells. Investigation of $\mathrm{ADE}$ using in vitro models showed that ADE occurs in a variety of primary cell cultures and cell lines, including human plasmacytoid DCs, mature DCs, and monocytes. All cell types identified from in vivo histology as dengue target cells bear FcR, and all of them support $\mathrm{ADE}$ in in vitro experiments. Using monocytes as an example, infection of DENV in the absence of immune sera was less than $1 \%$, but in the presence of sera Abs, infection can increase to $>10$-fold [53]. To address the role of ADE in dengue disease pathogenesis, sera from the subjects living in the endemic regions of the world who were enrolled in prospective cohort studies were evaluated in in vitro ADE assays. The ADE titers in preillness sera did not correlate with the clinical severity or viral burden of secondary DENV infection [54], suggesting other factors are important in the pathogenesis of DENV infection. Some of these factors could be the innate immune responses triggered by ICs of Ab-DENV.

\section{Innate Immune Responses}

4.1. Immune Complexes (IC) Triggered Innate Immunity. The majority of ICs formed between Abs and pathogens are cleared from the circulation in the liver and spleen by $M \Phi$. The IC can be phagocytosed through binding to FcR expressed by phagocytic cells, and the result is the degradation of the pathogens by enzymatic activities in the lysosomal compartments. Secondarily, foreign antigens expressed on the cell surface (e.g., Ab-DENV bound to FcR on cell surface, NS-1 expressed by infected cells) can be recognized by NK cells, triggering a killing mechanism known as Ab-dependent cellular cytotoxicity (ADCC) which results in the killing of infected cells [55]. Further, IC can activate the complement system which damages the infected cells, restricting virus propagation in infected cells [56]. All of these mechanisms of innate immunity are activated immediately upon pathogen invasion and play important roles in controlling pathogenic infection. At the meantime, the killing of target cells is associated with inflammatory cytokine/chemokine responses [57-59].

The effect of ADCC with respect to its protective role against DENV secondary infection has been documented. A study evaluated the level of ADCC in a ${ }^{51} \mathrm{Cr}$-release assay using preexisting DENV-positive plasma obtained prior to heterologous secondary DENV-2 and -3 infections through a prospective cohort study of the Thai school children. The principal of this study is the IC formed on the infected cell surface (plasma Abs bind to DENV antigens expressed by infected cells) are recognized by the FcR (CD16) on the NK cells, leading to NK cell killing of DENV-infected cells. Results showed that higher ADCC activities associated with higher plasma neutralizing Ab activities. Higher ADCC activity in presecondary DENV3 infection plasma samples correlated with lower plasma viremia levels, although this correlation was not seen with presecondary DENV2 infection plasma samples. No overt association was seen between ADCC activity and the clinical outcomes of disease severity in secondary infections, but the lowest ADCC activities were found to correlate with DHF of DENV-3 secondary infections. ADCC may contribute to the early control of secondary DV3 viremia in vivo [60].

DENV IC can activate complement pathway. A study used a total of 33 E-specific MAbs against DENV2 and 43 against DENV4 to study ADE showed that all MAbs enhanced infection at subneutralizing doses under normal ADE assay conditions where test samples were heat inactivated. However, the inclusion of commercial rabbit complement or fresh sera from healthy humans in the ADE assay system abolished the ADE activities of all these MAbs. Complement Clqor C3-depleted sera had a little effect on the elimination of ADE. Fresh human sera tended to eliminate ADE more effectively in homologous than heterologous viruses [61]. The complement component $\mathrm{Clq}$ restricts $\mathrm{ADE}$ by anti-Flavivirus Abs in an IgG subclass-specific manner in cell cultures and mice. IgG subclasses that bind $\mathrm{Clq}$ avidly induce minimal $\mathrm{ADE}$ in the presence of $\mathrm{Clq}$, whereas subclasses that bind $\mathrm{Clq}$ weakly enhance infection strongly [62]. On the other hand, the complement system is activated in DHF/DSS. The peak of activation and the presence of $\mathrm{C} 3 \mathrm{a}$ and $\mathrm{C} 5 \mathrm{a}$ anaphylatoxins coincided with the onset of shock and leakage. The levels of C3a correlated well with disease severity. This indicated an important role of the complement system in the pathogenesis of shock [63].

Innate immunity triggered by the Ab-DENV IC may play a role in dengue disease severity. There are 4 isotypes of IgG in human serum: IgG1 makes up most of (65\%) the total IgG in human serum, followed by IgG2 and then IgG3 and IgG4. The amounts of serum IgG3 and IgG4 are similar. IgG1 usually binds to FcR with greater affinity than IgG2. There are three major subclasses of FcR: Fc $\gamma$ RI (CD64), expressed on monocytes, $\mathrm{M} \Phi$, neutrophils, myeloid precursors, and DCs; Fc $\gamma$ RII, the most widely distributed human Fc $\gamma$ R type, expressed on most types of blood leukocytes, DCs, and platelets; and Fc $\gamma$ RIII (CD16) is expressed on NK cells and 
$\mathrm{M} \Phi$ [47]. Fc $\gamma \mathrm{R}$ I has high affinity for monomeric human IgG1 and IgG3 and low affinity for IgG4; is not binding to IgG2. $\mathrm{F} c \gamma \mathrm{RII}$ is a low-affinity receptor which only binds aggregated IgG. It is the only Fc $\gamma$ R class able to bind IgG2.

Due to structural characteristics of Ig isotypes and FcgR, the functional property of each Ig isotype is different. IgG1 and IgG3 can fix complement much more effectively than that of IgG2 [2, 5]. Kinetics and levels of lgG1-4 against each DENV serotype from patients with DF, DHF, and DSS have been studied. IgG1 and IgG3 serum Abs were the predominant Ig throughout the course of illness in all patients. Serum levels of IgG1 and IgG3 are significantly higher in DHF, and DSS patients than in DF patients $[64,65]$. In opposite, IgG2 are significantly lower in DHF and DSS patients than in DF patients [64]. Significant difference of IgG4 was also found between the DHF/DSS and DF patients [65]. The role FcR polymorphism in dengue pathogenesis is also being explored. Fc $\gamma$ R II A has two codominantly expressed alleles R131 and H131, which differs at 2 amino acids at positions 27 and 131. R131 and H131 differ significantly in binding to IgG2 and IgG3. Low binding homozygotes R131 of the Fc $\gamma$ R IIa are implied in protection from DHF [66].

Strategies to reduce IgG-Fc $\gamma$ R binding to minimize ADE were explored by altering the $\mathrm{Ab} F \mathrm{~F}$ structures responsible for binding to Fc receptors. IgG $1 \mathrm{~A} 5$ variants, containing amino acid substitutions from the Fc region of IgG2 or IgG4 antibodies, reduced but did not eliminate DENV-4enhancing activity in K562 cells. Importantly, a 9-aa deletion at the $\mathrm{N}$ terminus of the $\mathrm{CH}_{2}$ domain in the $\mathrm{Fc}$ region abrogated the enhancing activity [67].

These studies suggested that Ab-neutralization and ADE of DENV are more complicated events. It is a balance of many factors: the concentration and specificity of the Ab, the Ig isotypes of the $\mathrm{Ab}$, the receptor and host cell type, the complement and ADCC, and so forth. The fact that the addition of complement in a conventional plaque reduction neutralization test (PRNT) can turn nonneutralizing $\mathrm{Ab}$ to neutralize viral infection suggests that nonoptimal Abs depend on complement and the innate immune system to control viremia. The activation of ADCC and complement fixation may occur immediately upon viral infection, resulting in a strong inflammatory response, for example, $\mathrm{NK}$ cell and macrophages activation and inflammatory cytokine/chemokine production, thus predisposing patients with more cell/tissue damage.

The current widely used approaches, such as PRNT or ADE assays, addressed only partial functionality of DENV immune sera. Future efforts should be made to understand the contribution of innate immune activities triggered by DENV-Ab IC to the Ab-neutralization/enhancement, and to disease pathogenesis.

\subsection{DENV Infection and Cell Maturation/Activation and} Cytokine Production. DCs, monocytes, and M $\Phi$ are groups of heterogeneous bone-marrow-derived cells that are classified as important members of the innate immune system. DENV infection of these cells induces cytokine production and cell activation and maturation.
The production of IL-6, IL-8, IP-10, and TNF- $\alpha$ in DENVinfected monocytes was found to correlate with maximum virus production. DENV infection through the mechanism of $\mathrm{ADE}$ shows to induce the production of IFN- $\alpha$, TNF- $\alpha$, and IL-10 and upregulation of costimulatory markers CD40 and CD86, in primary in vitro monocyte cultures [53]. In vivo [68], the numbers of $\mathrm{CD}_{1}{ }^{+}$monocytes expressing the adhesion molecule intercellular adhesion molecule 1 (ICAM-1), TLR2, TLR4, and CD16 were increased during the acute stage of DF. The two major types of blood monocytes, CD14 ${ }^{++}$ $\mathrm{CD}_{16}{ }^{-}$and the $\mathrm{CD} 14^{+} \mathrm{CD} 16^{+}$, show distinct phenotype and function: $\mathrm{CD}_{1}{ }^{+} \mathrm{CD}_{1}{ }^{+}$are proinflammatory and have a higher expression of proinflammatory cytokines and higher potency in antigen presentation, and they rise in numbers in many disease processes [69]. It is not clear why this subset is increased in DF patients but not in DHF patients.

In humans, two major lineages of human dendritic cells have been studied extensively: myeloid DC ( $\mathrm{Lin}^{-} \mathrm{CD} 11 \mathrm{c}^{+}$ CD123 ${ }^{\text {med }}$ ) and plasmacytoid DC ( Lin $^{-} \mathrm{CD} 11 c^{-} \mathrm{CD} 123^{\text {high }}$ ). Myeloid DCs are distributed in various tissues that provide an environmental interface, such as skin (Langerhans cells), mucosal tissues of nose, lung, stomach, and intestine, where they filter antigens and become sensitized. It is suggested that dermal DCs are primary target cells when DENV is first injected into the skin by a mosquito bite. Most of the DC studies relating to DENV were carried out using cells derived from blood monocytes in vitro under the influence of IL-4 and GM-CSF [35, 70-72] or cells migrated from explanted skin patches in culture $[73,74]$. These studies showed that DENV-infected DCs produce inflammatory cytokines, TNF$\alpha$, IFN- $\alpha$, IL- 6 , regulatory cytokine IL-10, and chemokines IFN- $\gamma$-inducible chemokines CXCL9, 10, 11; IL-12p70 is not produced by DENV-infected DCs unless costimulatory ligand or inflammatory cytokine (IFN- $\gamma$ ) are present $[72,75]$. DENV is capable of impairing DC maturation and suppress T-cell proliferation $[75,76]$. Infection of plasmacytoid DCs by DENV is not as apparent as myeloid DCs, because the infection rate (percent of infected cells in a culture) determined by MAb-staining is very low. However, DENV replication in plasmacytoid DCs is confirmed by confocal microscope [77] and by the detection of negative stranded RNA [34]. Vigorous production of type-I IFN (IFN- $\alpha$ ) was seen in DENV-infected plasmacytoid DC cultures.

The ability of DENV-infected $M \Phi$ to induce permeability changes in primary human HUVEC was investigated. Supernatants from DENV-2-infected MФ increased permeability in HUVEC monolayers without infecting HUVEC cells. Although permeability induction was enhanced by preincubation with supernatants from infected $M \Phi$ harvested at the time of peak release of TNF- $\alpha$ and infectious virus, TNF$\alpha$ does not seem to be responsible for HUVEC permeability in this study. Nevertheless, this model system can be used for further in vitro analysis of mechanisms that may relate to capillary leakage and the development of DHF/DSS [78].

TLRs are pattern recognition receptors employed by the innate immune system to recognize pathogen-associated molecular patterns broadly shared by groups of microbes. Among 11 TLRs identified so far, three TLRs, TLR3, 7, and 8, 
are important for sensing invasion of RNA viruses. TLR3 recognizes double stranded RNA, whereas TLR7 and 8 recognize single stranded RNA. The downstream signaling events of TLRs activate the type I IFN (IFN- $\alpha / \beta)$ transcription factors and the production of IFNs. DENV is a single stranded RNA virus, and its replication relies on the formation of double stranded RNA intermediates. It is shown that TLR7 is required to recognize DENV in plasmacytoid DCs [70] for type I IFN production. TLR3 is responsible for recognition of DENV and triggering cytokine production in human monocytic cell line U937. Colocalization of TLR3 and DENV RNA upon DENV internalization was observed. TLR3 can mediate strong IFN- $\alpha / \beta$ release to inhibit DENV replication, thus limit the cytopathic effect [79]. TLR2 and TLR4, which recognize mostly glycan-lipids, were also suggested in the activation of monocytes upon DENV infection and inflammatory cytokine production [68].

Apoptosis and cytokine profiles have been used in in vitro models for assessing virulence of $\mathrm{DENV}$ isolates. It seemed that more virulent DENV isolates cause more extensive cell apoptosis [80] and induce higher amounts of cytokine/chemokine production. Infection of human monocyte-derived DC with a clinical isolates from a nonfatal case of DF from Brazil in 2002 and a fatal case with visceral complications from Paraguay in 2007 showed that the strain from fatal case display significantly higher replicative ability than that of the nonfatal case. In addition, the strain of fatal case elicited increased the production of proinflammatory cytokines and higher rates of cell apoptosis [81]. In consistency with these observations, higher serum levels of inflammatory cytokines/chemokines (TNF- $\alpha$, IFN- $\alpha$, IL1, IL-6, IL-8, IL-10, etc.) have been found in DHF patients versus DF patients. Therefore, apoptosis, cell activation, and cytokine production may directly contribute to the clinical manifestation of dengue diseases.

4.3. Apoptosis of DENV-Infected Cells. Apoptosis is documented in almost every single type of cells infected by $\mathrm{DENV}$ in vitro $[76,82]$ and in vivo. In vitro, apoptosis was documented in DENV-infected DCs, monocytes/MФ, hepatocytes, endothelial cells, and so forth. Apoptosis of infected monocytes was found hours after infection with nuclear condensation and fragmentation, cellular shrinkage, blebbing, and budding. Nuclear DNA degradation was confirmed by TdT-mediated dUTP nick-end labeling (TUNEL) technique [83]. In vivo, apoptosis was studied by colabeling the cells with TUNEL agents and DENV antigens in an immunohistochemical assay. During a DENV-2 outbreak in Santiago de Cuba in 1997, apoptotic cells were found in five of the six fatal cases studied. Apoptosis was demonstrated in liver, brain, and intestinal and lung tissues, in cerebral cells, white blood cells, intestinal and pulmonary microvascular endothelial cells (ECs) [84]. It is speculated that the apoptosis of microvascular ECs in pulmonary and intestinal tissues is related to vascular plasma leakage.

Apoptosis is a mechanism of cell death involved in the regulation of tissue homeostasis. The two major pathways of apoptosis are the extrinsic (death-receptor dependent signaling pathway) and the intrinsic (mitochondria-associated) pathways, both of which are found in the cytoplasm. The death-receptor dependent signaling pathway (also known as the TNFR-mediated apoptosis pathway) [85] involves death receptors such as Fas, DR3, TNFR-1 and -2, DR4, DR5, DR6, and so forth. The ligands are FasL for Fas, TNF- $\alpha$ for TNFR-1 and -2, TNF-related apoptosis-inducing ligand (TRAIL), and so forth. Apoptosis is initiated by binding the ligand to receptor, clustering the receptors on the cell surface, triggering a stream of intracellular signaling events involving FADD (Fas-associating protein with death domain), DISC (death-inducing signaling complex), and a set of caspases, leading to the degradation of cellular proteins necessary to maintain cell survival and integrity. The intrinsic pathway occurs when various apoptotic stimuli trigger the release of cytochrome $\mathrm{C}$ from the mitochondria (independently of caspase- 8 activation). Cytochrome $C$ interacts with Apaf-1 and caspase- 9 to promote the activation of caspase-3. Recent studies point to the ER as a third organelle implicated in apoptosis. The primary function of the ER is to facilitate protein folding and secretion. A number of stress conditions can lead to accumulation of unfolded and/or misfolded proteins, which interfere with ER's function, a condition termed "ER stress." As a result, cells activate an integrated intracellular signaling cascade, the UPR, to avert ER stress. However, prolonged ER stress can activate cell apoptosis.

The pathways that lead to the apoptosis of DENVinfected cells have been studied in vitro. Results indicated that a combination of these pathways may work together. DENV-induced apoptosis mediated by the unfolded protein response (UPR) has been evaluated A549 cells. Upon DENV infection, A549 cells elicit an UPR which is observed at the level of translation attenuation (as visualized by the phosphorylation of eIF2alpha) and activation of specific pathways such as nuclear translocation of ATF-6 and splicing of XBP-1. Modulators of UPR can inhibit DENV replication [86]. The death-receptor dependent signaling pathway was found to be involved in DENV-infected hepatic cell apoptosis [87]. Death-receptor dependent apoptosis pathway is also implicated in apoptosis of DENV-infected HUVEC cells [88]. The expression of cell death genes including RIPK2, HRK, TGF-beta, PERK, and LC3B during DENV-infection of HepG2 cells is consistent with the activation of apoptosis and autophagy [89]. RIPK2 belongs to the receptor-interacting protein family of serine/threonine protein kinases, which is a crucial mediator of multiple stress responses that leads to the activation of caspase, NF-kappaB, and MAP kinases including JNK and p38.

DENV C protein, NS3 protease (NS3pro), and NS2B-NS3 serine protease precursor protein (NS2B-NS3(185)(pro)) are implicated in apoptosis. The $\mathrm{C}$ protein physically interacts with the human death domain-associated protein Daxx. A double substitution mutation in DENV C (R85A/K86A) abrogates Daxx interaction, nuclear localization, and apoptosis. Expression of CD137, a member of the TNF receptor family, increased significantly in HepG2 cells expressing DENV C compared to HepG2 cells expressing DENV C (R85A/K86A) [90]. Human microvascular endothelial cells (HMEC-1) infected with a DENV-2 clinical isolate, or HMEC-1 cells transfected with NS3pro or NS2BNS3pro were 
able to trigger apoptosis after $24 \mathrm{~h}$ of infection or transfection: cytoplasmic shrinkage, plasma membrane blebbing, TUNEL positivity, caspase- 3 activation, and cleaved PARP, a central regulator of apoptosis [91]. Site-directed mutagenesis which replaced His(51) with Ala within the protease catalytic triad significantly weakens the NS3- and NS2B-NS3(185)(pro)induced cell apoptosis [92].

Apoptosis of peripheral blood mononuclear cells (PBMCs) was examined in cohorts of DF and DHF children. Around defervescence, PBMC apoptosis was higher in children with DHF, compared to DF and nondengue febrile cases. $\mathrm{CD}^{+}$T-lymphocytes comprised at least half of the peak apoptotic PBMC in children. Apoptosis was also found in DENV peptide-specific $\mathrm{CD}^{+} \mathrm{T}$ cells from patients with acute illness. One possible mechanism of T-cell apoptosis is the apoptosis of DENV-infected antigen presenting cells (dendritic cells, macrophages, etc.) which caused T-cell apoptosis.

It is common for a virus to infect a cell and trigger its programmed cell death pathway. Apoptosis is considered a host defense mechanism. Sudden cell death triggers the immune system to remove cells harboring harmful pathogens. However, it may also maximize viral spread from lytic cells. Many viruses have been shown to trigger apoptotic cell death and/or encode inhibitors of apoptosis. Although these viral factors have been studied in great molecular detail, it is less clear how these factors contribute to innate defense or disease pathogenesis.

\section{T-Cell Responses to DENV}

Cell mediated immunity is comprised of two major subsets of the T cells, CD4 and CD8. CD4 ${ }^{+} \mathrm{T}$ cells exert functions as helpers for other $\mathrm{T}$ cells and $\mathrm{B}$ cells, whereas $\mathrm{CD} 8^{+}$exerts cytotoxic function. $\mathrm{CD} 4^{+} \mathrm{T}$ cells can be divided into Th1 and Th2 subtypes based on their cytokine profiles. Th1 cells produce IFN- $\gamma$, TNF- $\alpha$, and IL-2; Th 2 cells produce IL- 4 , IL5 , IL-10, and IL-13. The IFN- $\gamma$ and TNF- $\alpha$ can have a direct killing effect on intracellular pathogens while IL-2 is required for helping with T-cell proliferation. Therefore, Th1 response is important for antibacterial and antiviral immune defense. $\mathrm{CD}^{+} \mathrm{T}$ cells can directly recognize and kill infected cells through cytotoxicity (CTL) and antiviral cytokines such as IFN- $\gamma$. Recently, it was shown that a strong polyfunctional $\mathrm{CD}^{+} \mathrm{T}$ cell response capable of coproducing TNF- $\alpha$ and IL2 in additional to IFN- $\gamma$ [93-95] was required to control the progressive infection of viruses like HIV and HCV.

The major target cells for DENV, monocytes, $\mathrm{M} \Phi$, and DC are APCs critical for stimulating cell mediated immunity. Targeting these cells by DENV may have an unfavorable impact on host adaptive immunity. In vitro, infected DCs promote IFN- $\gamma$ production from T cells $[71,72,75,82,96]$. However, the response is altered. It is shown that DENV-infected DCs are incapable to prime a mixed lymphocytes reaction (MLR) [82]. Others showed that DENV-infected DCs induced initial proliferation of naive $\mathrm{CD}^{+} \mathrm{T}$ cells, but they remained nonpolarized in effector function. The expression of IFN$\alpha / \beta$-stimulated genes was downregulated [97]. In naturally infected humans during acute disease stages, it seems that cellular immunity is not fully activated and apoptosis is observed based on the following observations: impairment of $\mathrm{CD}^{+} \mathrm{T}$-cell cytokine production [98], decreased circulating of $\mathrm{CD}^{+}$and $\mathrm{CD}^{+}$T-cell counts [99], impairment of Tcell proliferation $[100,101]$, and increased T-cell apoptosis. The in vitro studies on DENV-infected DCs supported these observations showing that DC maturation was abolished and apoptosis was observed, and T-cell proliferation was significantly suppressed $[75,82]$.

In vivo, the T-cell activities, T-cell counts, and cytokine production are all restored after the early illness (day 5 and on) at the time when viremia declines [98-101]. Often, the amount of DENV-specific $\mathrm{T}$ cells, measured by cytokine assays and tetramer staining, recovered from DHF patients are higher than that of DF patients; therefore, cellular immunity is currently considered to play a pathological role [102104]. By examining the intracellular cytokine profile, the ratio of IFN- $\gamma /$ IL- 4 and the percentage of Mip- $1^{+}$CD8 T cells are found higher in DHF patients than in DF patients [105], suggesting a Thl-type of memory cell response. Tcell responses in a cohort of dengue-infected children from Thailand are found to target to most of the 10 viral proteins. However, responses to NS3 is the most dominant, and there is a very strong association between the magnitude of the response to NS3 with disease severity [102]. Specifically, the cross-reactive memory $\mathrm{T}$ cells recovered from dengue illness exhibited higher affinity to variant epitopes representing serotypes of previous exposure-a phenomenon termed "original antigenic sin" [98].

A major limitation for understanding DENV-specific immune responses is associated with the study design in those studies that have used samples taken from patients in the acute phase of their illness through their recovery period rather than samples obtained prior to the infectious process $[98,101,102,106,107]$. More importantly, those studies did not include asymptomatic secondary infections; therefore, they did not address the role of cellular immunity in immune protection; rather, they emphasized a correlation between antidengue cellular immunity with disease severity. An unbiased natural infection model that includes preinfection samples from both asymptomatic and symptomatic infections is needed to correct this bias. This can be accomplished through a longitudinal cohort design where scheduled blood collection is carried out in a human cohort that is monitored for disease and seroconversions. To our knowledge, only two studies published by the same group described preexisting cellular immunity in subclinical infections $[108,109]$. ReyesDel Valle et al. reported a higher proportion of IFN- $\gamma$ and IL-2 responses to DENV-3 antigen among persons with subclinical infections compared to those with symptomatic infections. The study suggested that IL-2 maybe an important cytokine for immune protection [26].

\section{Summary and Future Prospective}

Significant progresses have been made regarding viral and host cellular molecules involved in DENV-receptor interaction and infection. However, the dynamic process of DENV tropism during different stages of DENV infection, the 
preference of receptors and host cells involved in the primary or secondary, and in early or late stages of DENV infections, are not clearly understood. Most importantly, the role of glycosylation with respect to receptor binding, viral tropism, and virulence of infectivity is not well understood. Current Abmediated neutralization/enhancement studies rarely include innate immune mechanism, such as complement activation and ADCC. Future studies should target into these challenging areas. Further, future studies on adaptive humoral and cellular immunity should use a unique population: those who experienced DENV asymptomatic infections, to better address the protective immunity.

\section{Acknowledgments}

This work is supported by The MIDRP funding: S0210_09. The views expressed in this paper are those of the authors and do not necessarily reflect the official policy or position of the Department of the Navy, Department of Defense, or the US Government. T. Kochel is a military service member. This work was prepared as part of his official duties. Title 17 USC $\$ 105$ provides that "Copyright protection under this title is not available for any work of the United States Government." Title 17 USC \$101 defines a US Government work as a work prepared by a military service member or employee of the US Government as part of that person's official duties.

\section{References}

[1] A. C. Morrison, E. Zielinski-Gutierrez, T. W. Scott, and R. Rosenberg, "Defining challenges and proposing solutions for control of the virus vector Aedes aegypti," PLoS Medicine, vol. 5, no. 3, article e68, 2008.

[2] A. Mathew and A. L. Rothman, "Understanding the contribution of cellular immunity to dengue disease pathogenesis," Immunological Reviews, vol. 225, no. 1, pp. 300-313, 2008.

[3] S. B. Halstead, "Pathogenisis of dengue: challenges to molecular biology," Science, vol. 239, no. 4839, pp. 476-481, 1988.

[4] D. J. Gubler, "Surveillance for dengue and dengue hemorrhagic fever," Bulletin of the Pan American Health Organization, vol. 23, no. 4, pp. 397-404, 1989.

[5] D. H. Libraty, T. P. Endy, H. S. H. Houng et al., "Differing influences of virus burden and immune activation on disease severity in secondary dengue-3 virus infections," Journal of Infectious Diseases, vol. 185, no. 9, pp. 1213-1221, 2002.

[6] D. W. Vaughn, S. Green, S. Kalayanarooj et al., "Dengue viremia titer, antibody response pattern, and virus serotype correlate with disease severity," Journal of Infectious Diseases, vol. 181, no. 1, pp. 2-9, 2000.

[7] A. Srikiatkhachorn, "Plasma leakage in dengue haemorrhagic fever," Thrombosis and Haemostasis, vol. 102, no. 6, pp. 10421049, 2009.

[8] A. Srikiatkhachorn, A. Krautrachue, W. Ratanaprakarn et al., "Natural history of plasma leakage in dengue hemorrhagic fever: a serial ultrasonographic study," Pediatric Infectious Disease Journal, vol. 26, no. 4, pp. 283-290, 2007.

[9] S. Kalayanarooj, "Dengue classification: current WHO versus the newly suggested classification for better clinical application?" Journal of the Medical Association of Thailand, vol. 94, supplement 3, pp. 74-84.
[10] L. Thomas, Y. Brouste, F. Najioullah et al., "Prospective and descriptive study of adult dengue cases in an emergency department, in Martinique," Medecine et Maladies Infectieuses, vol. 40 , no. 8, pp. 480-489, 2010.

[11] M. M. Riaz, K. Mumtaz, M. S. Khan et al., "Outbreak of dengue fever in Karachi 2006: a clinical perspective," Journal of the Pakistan Medical Association, vol. 59, no. 6, pp. 339-344, 2009.

[12] G. S. Shah, S. Islam, and B. K. Das, "Clinical and laboratory profile of dengue infection in children," Kathmandu University Medical Journal, vol. 4, no. 13, pp. 40-43, 2006.

[13] S. Noisakran and G. C. Perng, "Alternate hypothesis on the pathogenesis of dengue hemorrhagic fever (DHF)/dengue shock syndrome (DSS) in dengue virus infection," Experimental Biology and Medicine, vol. 233, no. 4, pp. 401-408, 2008.

[14] T. H. Nguyen, T. L. Nguyen, H. Y. Lei et al., "Association between sex, nutritional status, severity of dengue hemorrhagic fever, and immune status in infants with dengue hemorrhagic fever," American Journal of Tropical Medicine and Hygiene, vol. 72, no. 4, pp. 370-374, 2005.

[15] H. P. Tee, S. H. How, A. R. Jamalludin et al., "Risk factors associated with development of dengue haemorrhagic fever or dengue shock syndrome in adults in Hospital Tengku Ampuan Afzan Kuantan," Medical Journal of Malaysia, vol. 64, no. 4, pp. 316-320, 2009.

[16] S. Green and A. Rothman, "Immunopathological mechanisms in dengue and dengue hemorrhagic fever," Current Opinion in Infectious Diseases, vol. 19, no. 5, pp. 429-436, 2006.

[17] J. A. Mondotte, P. Y. Lozach, A. Amara, and A. V. Gamarnik, "Essential role of dengue virus envelope protein N glycosylation at asparagine-67 during viral propagation," Journal of Virology, vol. 81, no. 13, pp. 7136-7148, 2007.

[18] M. J. Pryor, R. C. Gualano, B. Lin, A. D. Davidson, and P. J. Wright, "Growth restriction of dengue virus type 2 by sitespecific mutagenesis of virus-encoded glycoproteins," Journal of General Virology, vol. 79, no. 11, pp. 2631-2639, 1998.

[19] M. J. Pryor and P. J. Wright, "Glycosylation mutants of dengue virus NS1 protein,” Journal of General Virology, vol. 75, no. 5, pp. 1183-1187, 1994.

[20] P. Somnuke, R. E. Hauhart, J. P. Atkinson, M. S. Diamond, and P. Avirutnan, "N-linked glycosylation of dengue virus NS1 protein modulates secretion, cell-surface expression, hexamer stability, and interactions with human complement," Virology, vol. 413, no. 2, pp. 253-264, 2011.

[21] J. E. Bryant, A. E. Calvert, K. Mesesan et al., "Glycosylation of the dengue 2 virus E protein at N67 is critical for virus growth in vitro but not for growth in intrathoracically inoculated Aedes aegypti mosquitoes," Virology, vol. 366, no. 2, pp. 415-423, 2007.

[22] P. Sakoonwatanyoo, V. Boonsanay, and D. R. Smith, "Growth and production of the dengue virus in C6/36 cells and identification of a laminin-binding protein as a candidate serotype 3 and 4 receptor protein," Intervirology, vol. 49, no. 3, pp. 161-172, 2006.

[23] J. J. Martínez-Barragán and R. M. del Angel, "Identification of a putative coreceptor on Vero cells that participates in dengue 4 virus infection," Journal of Virology, vol. 75, no. 17, pp. 7818-7827, 2001.

[24] C. Thepparit and D. R. Smith, "Serotype-specific entry of dengue virus into liver cells: identification of the 37kilodalton/67-kilodalton high-affinity laminin receptor as a dengue virus serotype 1 receptor," Journal of Virology, vol. 78, no. 22 , pp. 12647-12656, 2004. 
[25] S. Jindadamrongwech, C. Thepparit, and D. R. Smith, "Identification of GRP $78(\mathrm{BiP})$ as a liver cell expressed receptor element for dengue virus serotype 2," Archives of Virology, vol. 149, no. 5, pp. 915-927, 2004.

[26] J. Reyes-Del Valle, S. Chávez-Salinas, F. Medina, and R. M. del Angel, "Heat shock protein 90 and heat shock protein 70 are components of dengue virus receptor complex in human cells," Journal of Virology, vol. 79, no. 8, pp. 4557-4567, 2005.

[27] A. Cabrera-Hernandez, C. Thepparit, L. Suksanpaisan, and D. R. Smith, "Dengue virus entry into liver (HepG2) cells is independent of hsp90 and hsp70," Journal of Medical Virology, vol. 79, no. 4, pp. 386-392, 2007.

[28] S. Upanan, A. Kuadkitkan, and D. R. Smith, "Identification of dengue virus binding proteins using affinity chromatography," Journal of Virological Methods, vol. 151, no. 2, pp. 325-328, 2008.

[29] Y. Chen, T. Maguire, R. E. Hileman et al., "Dengue virus infectivity depends on envelope protein binding to target cell heparan sulfate," Nature Medicine, vol. 3, no. 8, pp. 866-871, 1997.

[30] J. L. Miller, B. J. M. deWet, L. Martinez-Pomares et al., "The mannose receptor mediates dengue virus infection of macrophages," PLoS Pathogens, vol. 4, no. 2, article e17, 2008.

[31] H. Bielefeldt-Ohmann, M. Meyer, D. R. Fitzpatrick, and J. S. Mackenzie, "Dengue virus binding to human leukocyte cell lines: receptor usage differs between cell types and virus strains," Virus Research, vol. 73, no. 1, pp. 81-89, 2001.

[32] S. T. Chen, Y. L. Lin, M. T. Huang et al., "CLEC5A is critical for dengue-virus-induced lethal disease," Nature, vol. 453, no. 7195, pp. 672-676, 2008.

[33] A. A. Watson and C. A. O'callaghan, "Crystallization and Xray diffraction analysis of human CLEC5A (MDL-1), a dengue virus receptor," Acta Crystallographica F, vol. 66, no. 1, pp. 29-31, 2009.

[34] B. Tassaneetrithep, T. H. Burgess, A. Granelli-Piperno et al., "DC-SIGN (CD209) mediates dengue virus infection of human dendritic cells," Journal of Experimental Medicine, vol. 197, no. 7, pp. 823-829, 2003.

[35] M. Marovich, G. Grouard-Vogel, M. Louder et al., "Human dendritic cells as targets of dengue virus infection," Journal of Investigative Dermatology Symposium Proceedings, vol. 6, no. 3, pp. 219-224, 2001.

[36] P. Y. Lozach, L. Burleigh, I. Staropoli et al., "Dendritic cell-specific intercellular adhesion molecule 3-grabbing nonintegrin (DC-SIGN)-mediated enhancement of dengue virus infection is independent of DC-SIGN internalization signals," The Journal of Biological Chemistry, vol. 280, no. 25, pp. 2369823708, 2005.

[37] J. S. Salas-Benito and R. M. del Angel, "Identification of two surface proteins from C6/36 cells that bind dengue type 4 virus," Journal of Virology, vol. 71, no. 10, pp. 7246-7252, 1997.

[38] J. Salas-Benito, J. R. D. Valle, M. Salas-Benito, I. CeballosOlvera, C. Mosso, and R. M. del Angel, "Evidence that the 45-kD glycoprotein, part of a putative dengue virus receptor complex in the mosquito cell line C6/36, is a heat-shock-related protein," American Journal of Tropical Medicine and Hygiene, vol. 77, no. 2, pp. 283-290, 2007.

[39] R. Germi, J. M. Crance, D. Garin et al., "Heparan sulfatemediated binding of infectious dengue virus type 2 and yellow fever virus," Virology, vol. 292, no. 1, pp. 162-168, 2002.

[40] N. Dalrymple and E. R. Mackow, "Productive dengue virus infection of human endothelial cells is directed by heparan sulfate-containing proteoglycan receptors," Journal of Virology, vol. 85, no. 18, pp. 9478-9485, 2011.

[41] D. Kangwanpong, N. Bhamarapravati, and H. L. Lucia, "Diagnosing dengue virus infection in archived autopsy tissues by means of the in situ PCR method: a case report," Clinical and Diagnostic Virology, vol. 3, no. 2, pp. 165-172, 1995.

[42] J. M. G. de Araújo, H. G. Schatzmayr, A. M. B. de Filippis et al., "A retrospective survey of dengue virus infection in fatal cases from an epidemic in Brazil," Journal of Virological Methods, vol. 155, no. 1, pp. 34-38, 2009.

[43] A. P. Durbin, M. J. Vargas, K. Wanionek et al., "Phenotyping of peripheral blood mononuclear cells during acute dengue illness demonstrates infection and increased activation of monocytes in severe cases compared to classic dengue fever," Virology, vol. 376, no. 2, pp. 429-435, 2008.

[44] J. Mota and R. Rico-Hesse, "Dengue virus tropism in humanized mice recapitulates human dengue fever," PLoS ONE, vol. 6, no. 6, Article ID e20762, 2011.

[45] G. Añez, R. Men, K. H. Eckels, and C. J. Lai, "Passage of dengue virus type 4 vaccine candidates in fetal rhesus lung cells selects heparin-sensitive variants that result in loss of infectivity and immunogenicity in rhesus macaques," Journal of Virology, vol. 83, no. 20, pp. 10384-10394, 2009.

[46] S. Shresta, K. L. Sharar, D. M. Prigozhin, P. R. Beatty, and E. Harris, "Murine model for dengue virus-induced lethal disease with increased vascular permeability," Journal of Virology, vol. 80, no. 20, pp. 10208-10217, 2006.

[47] T. R. Prestwood, D. M. Prigozhin, K. L. Sharar, R. M. Zellweger, and S. Shresta, "A mouse-passaged dengue virus strain with reduced affinity for heparan sulfate causes severe disease in mice by establishing increased systemic viral loads," Journal of Virology, vol. 82, no. 17, pp. 8411-8421, 2008.

[48] E. J. Ryan, M. Dring, C. M. Ryan et al., "Variant in CD209 promoter is associated with severity of liver disease in chronic hepatitis C virus infection," Human Immunology, vol. 71, no. 8, pp. 829-832, 2010.

[49] L. Wang, R. F. Chen, J. W. Liu et al., "DC-SIGN (CD209) promoter $-336 \mathrm{~A} / \mathrm{G}$ polymorphism is associated with dengue hemorrhagic fever and correlated to DC-SIGN expression and immune augmentation," PLoS Neglected Tropical Diseases, vol. 5, no. 1, article e934, 2011.

[50] P. K. Russell, S. Udomsakdi, and S. B. Halstead, "Antibody response in dengue and dengue hemorrhagic fever," Japanese Journal of Medical Science and Biology, vol. 20, pp. 103-108, 1967.

[51] M. G. Guzmán, G. Kourí, L. Valdés, J. Bravo, S. Vázquez, and S. B. Halstead, "Enhanced severity of secondary dengue2 infections: death rates in 1981 and 1997 Cuban outbreaks," Revista Panamericana de Salud Publica, vol. 11, no. 4, pp. 223227, 2002.

[52] S. C. Kliks, S. Nimmanitya, A. Nisalak, and D. S. Burke, "Evidence that maternal dengue antibodies are important in the development of dengue hemorrhagic fever in infants," American Journal of Tropical Medicine and Hygiene, vol. 38, no. 2, pp. 411419, 1988.

[53] P. Sun, K. Bauza, S. Pal et al., "Infection and activation of human peripheral blood monocytes by dengue viruses through the mechanism of antibody-dependent enhancement," Virology, vol. 421, no. 2, pp. 245-252.

[54] K. Laoprasopwattana, D. H. Libraty, T. P. Endy et al., "Dengue virus (DV) enhancing antibody activity in preillness plasma does not predict subsequent disease severity or viremia in 
secondary DV infection," Journal of Infectious Diseases, vol. 192, no. 3, pp. 510-519, 2005.

[55] A. Stokes and R. C. Wardley, "ADCC and complementdependent lysis as immune mechanisms against EHV-1 infection in the horse," Research in Veterinary Science, vol. 44, no. 3 , pp. 295-302, 1988.

[56] G. Fust, "The biological role of the complement system and the clinical importance of complement measurements," Haematologia, vol. 12, no. 1-4, pp. 85-106, 1978.

[57] A. Iannello, O. Debbeche, S. Samarani, and A. Ahmad, "Antiviral NK cell responses in HIV infection: I. NK cell receptor genes as determinants of HIV resistance and progression to AIDS," Journal of Leukocyte Biology, vol. 84, no. 1, pp. 1-26, 2008.

[58] H. Stoiber, A. Soederholm, D. Wilflingseder, S. Gusenbauer, A. Hildgartner, and M. P. Dierich, "Complement and antibodies: a dangerous liaison in HIV infection?” Vaccine, vol. 26, no. 8, pp. I79-I85, 2008.

[59] J. H. Anolik, "B cell biology and dysfunction in SLE," Bulletin of the NYU Hospital for Joint Diseases, vol. 65, no. 3, pp. 182-186, 2007.

[60] K. Laoprasopwattana, D. H. Libraty, T. P. Endy et al., "Antibodydependent cellular cytotoxicity mediated by plasma obtained before secondary dengue virus infections: potential involvement in early control of viral replication," Journal of Infectious Diseases, vol. 195, no. 8, pp. 1108-1116, 2007.

[61] A. Yamanaka, S. Kosugi, and E. Konishi, "Infection-enhancing and -neutralizing activities of mouse monoclonal antibodies against dengue type 2 and 4 viruses are controlled by complement levels," Journal of Virology, vol. 82, no. 2, pp. 927-937, 2008.

[62] E. Mehlhop, C. Ansarah-Sobrinho, S. Johnson et al., "Complement protein Clq inhibits antibody-dependent enhancement of flavivirus infection in an IgG subclass-specific manner," Cell Host and Microbe, vol. 2, no. 6, pp. 417-426, 2007.

[63] P. Malasit, "Complement and dengue haemorrhagic fever/shock syndrome," The Southeast Asian Journal of Tropical Medicine and Public Health, vol. 18, no. 3, pp. 316-320, 1987.

[64] S. Thein, J. Aaskov, T. Myint, T. N. Shwe, T. T. Saw, and A. Zaw, "Changes in levels of anti-dengue virus IgG subclasses in patients with disease of varying severity," Journal of Medical Virology, vol. 40, no. 2, pp. 102-106, 1993.

[65] P. Koraka, C. Suharti, T. E. Setiati et al., "Kinetics of dengue virus-specific serum immunoglobulin classes and subclasses correlate with clinical outcome of infection," Journal of Clinical Microbiology, vol. 39, no. 12, pp. 4332-4338, 2001.

[66] H. Loke, D. Bethell, C. X. T. Phuong et al., "Susceptibility to dengue hemorrhagic fever in Vietnam: evidence of an association with variation in the vitamin D receptor and FC $\gamma$ receptor IIA genes," American Journal of Tropical Medicine and Hygiene, vol. 67, no. 1, pp. 102-106, 2002.

[67] A. P. Goncalvez, R. E. Engle, M. S. Claire, R. H. Purcell, and C. J. Lai, "Monoclonal antibody-mediated enhancement of dengue virus infection in vitro and in vivo and strategies for prevention," Proceedings of the National Academy of Sciences of the United States of America, vol. 104, no. 22, pp. 9422-9427, 2007.

[68] E. L. Azeredo, P. C. Neves-Souza, A. R. Alvarenga et al., "Differential regulation of toll-like receptor-2, toll-like receptor4, CD16 and human leucocyte antigen-DR on peripheral blood monocytes during mild and severe dengue fever," Immunology, vol. 130, no. 2, pp. 202-216, 2010.
[69] L. Ziegler-Heitbrock, "The CD14+ CD16+ blood monocytes: their role in infection and inflammation," Journal of Leukocyte Biology, vol. 81, no. 3, pp. 584-592, 2007.

[70] P. Sun, S. Fernandez, M. A. Marovich et al., "Functional characterization of ex vivo blood myeloid and plasmacytoid dendritic cells after infection with dengue virus," Virology, vol. 383 , no. 2, pp. 207-215, 2009.

[71] L. J. Ho, J. J. Wang, M. F. Shaio et al., "Infection of human dendritic cells by Dengue virus causes cell maturation and cytokine production," Journal of Immunology, vol. 166, no. 3, pp. 1499-1506, 2001.

[72] D. H. Libraty, S. Pichyangkul, C. Ajariyakhajorn, T. P. Endy, and F. A. Ennis, "Human dendritic cells are activated by dengue virus infection: enhancement by gamma interferon and implications for disease pathogenesis," Journal of Virology, vol. 75, no. 8, pp. 3501-3508, 2001.

[73] A. Y. Limon-Flores, M. Perez-Tapia, I. Estrada-Garcia et al., "Dengue virus inoculation to human skin explants: an effective approach to assess in situ the early infection and the effects on cutaneous dendritic cells," International Journal of Experimental Pathology, vol. 86, no. 5, pp. 323-334, 2005.

[74] W. H. Kwan, A. M. Helt, C. Marañón et al., "Dendritic cell precursors are permissive to dengue virus and human immunodeficiency virus infection," Journal of Virology, vol. 79, no. 12, pp. 7291-7299, 2005.

[75] P. Sun, C. M. Celluzzi, M. Marovich et al., "CD40 ligand enhances dengue viral infection of dendritic cells: a possible mechanism for T cell-mediated immunopathology," Journal of Immunology, vol. 177, no. 9, pp. 6497-6503, 2006.

[76] Z. D. Nightingale, C. Patkar, and A. L. Rothman, "Viral replication and paracrine effects result in distinct, functional responses of dendritic cells following infection with dengue 2 virus," Journal of Leukocyte Biology, vol. 84, no. 4, pp. 1028-1038, 2008.

[77] S. Pichyangkul, T. P. Endy, S. Kalayanarooj et al., "A blunted blood plasmacytoid dendritic cell response to an acute systemic viral infection is associated with increased disease severity," Journal of Immunology, vol. 171, no. 10, pp. 5571-5578, 2003.

[78] J. M. Carr, H. Hocking, K. Bunting et al., "Supernatants from dengue virus type- 2 infected macrophages induce permeability changes in endothelial cell monolayers," Journal of Medical Virology, vol. 69, no. 4, pp. 521-528, 2003.

[79] Y. T. Tsai, S. Y. Chang, C. N. Lee, and C. L. Kao, "Human TLR3 recognizes dengue virus and modulates viral replication in vitro," Cellular Microbiology, vol. 11, no. 4, pp. 604-615, 2009.

[80] A. Tuiskunen, V. Monteil, S. Plumet et al., "Phenotypic and genotypic characterization of dengue virus isolates differentiates dengue fever and dengue hemorrhagic fever from dengue shock syndrome," Archives of Virology, vol. 156, no. 11, pp. 2023 2032, 2011.

[81] G. F. Silveira, F. Meyer, A. Delfraro et al., "Dengue virus type 3 isolated from a fatal case with visceral complications induces enhanced proinflammatory responses and apoptosis of human dendritic cells," Journal of Virology, vol. 85, no. 11, pp. 5374-5383, 2011.

[82] D. R. Palmer, P. Sun, C. Celluzzi et al., "Differential effects of dengue virus on infected and bystander dendritic cells," Journal of Virology, vol. 79, no. 4, pp. 2432-2439, 2005.

[83] J. A. Mosquera, J. P. Hernandez, N. Valero, L. M. Espina, and G. J. Añez, "Ultrastructural studies on dengue virus type 2 infection of cultured human monocytes," Virology Journal, vol. 2, article 26, 2005. 
[84] D. Limonta, V. Capó, G. Torres, A. B. Pérez, and M. G. Guzmán, "Apoptosis in tissues from fatal dengue shock syndrome," Journal of Clinical Virology, vol. 40, no. 1, pp. 50-54, 2007.

[85] M. P. Courageot, A. Catteau, and P. Desprès, "Mechanisms of Dengue virus-induced cell death," Advances in Virus Research, vol. 60, pp. 157-186, 2003.

[86] I. Umareddy, O. Pluquet, Q. Y. Wang, S. G. Vasudevan, E. Chevet, and F. Gu, "Dengue virus serotype infection specifies the activation of the unfolded protein response," Virology Journal, vol. 4, article 91, 2007.

[87] T. Matsuda, A. Almasan, M. Tomita et al., "Dengue virusinduced apoptosis in hepatic cells is partly mediated by Apo2 ligand/tumour necrosis factor-related apoptosis-inducing ligand," Journal of General Virology, vol. 86, no. 4, pp. 1055-1065, 2005.

[88] H. Liao, J. Xu, and J. Huang, "FasL/Fas pathway is involved in dengue virus induced apoptosis of the vascular endothelial cells," Journal of Medical Virology, vol. 82, no. 8, pp. 1392-1399, 2010.

[89] A. Morchang, U. Yasamut, J. Netsawang et al., "Cell death gene expression profile: role of RIPK2 in dengue virus-mediated apoptosis," Virus Research, vol. 156, no. 1-2, pp. 25-34, 2011.

[90] A. Nagila, J. Netsawang, C. Srisawat et al., "Role of CD137 signaling in dengue virus-mediated apoptosis," Biochemical and Biophysical Research Communications, vol. 410, no. 3, pp. 428433, 2011.

[91] M. V. Ochoa, J. G. Cordero, B. G. Castañeda, L. S. Argumedo, N. V. Sepúlveda, and L. C. Barrón, "A clinical isolate of dengue virus and its proteins induce apoptosis in HMEC-1 cells: a possible implication in pathogenesis," Archives of Virology, vol. 154, no. 6, pp. 919-928, 2009.

[92] N. Shafee and S. AbuBakar, "Dengue virus type 2 NS3 protease and NS2B-NS3 protease precursor induce apoptosis," Journal of General Virology, vol. 84, no. 8, pp. 2191-2195, 2003.

[93] P. Kiepiela, K. Ngumbela, C. Thobakgale et al., "CD8 ${ }^{+}$T-cell responses to different HIV proteins have discordant associations with viral load," Nature Medicine, vol. 13, no. 1, pp. 46-53, 2007.

[94] J. S. Yi, M. A. Cox, and A. J. Zajac, "T-cell exhaustion: characteristics, causes and conversion," Immunology, vol. 129, no. 4, pp. 474-481, 2010.

[95] M. A. Cox and A. J. Zajac, "Shaping successful and unsuccessful CD8 T cell responses following infection," Journal of Biomedicine and Biotechnology, vol. 2010, Article ID 159152, 12 pages, 2010.

[96] W. Dejnirattisai, T. Duangchinda, C. L. S. Lin et al., "A complex interplay among virus, dendritic cells, T cells, and cytokines in dengue virus infections," Journal of Immunology, vol. 181, no. 9, pp. 5865-5874, 2008.

[97] A. J. Chase, F. A. Medina, and J. L. Muñoz-Jordán, "Impairment of $\mathrm{CD} 4^{+} \mathrm{T}$ cell polarization by dengue virus-infected dendritic cells," Journal of Infectious Diseases, vol. 203, no. 12, pp. 17631774, 2011.

[98] J. Mongkolsapaya, W. Dejnirattisai, X. N. Xu et al., "Original antigenic sin and apoptosis in the pathogenesis of dengue hemorrhagic fever," Nature Medicine, vol. 9, no. 7, pp. 921-927, 2003.

[99] S. Green, S. Pichyangkul, D. W. Vaughn et al., "Early CD69 expression on peripheral blood lymphocytes from children with dengue hemorrhagic fever," Journal of Infectious Diseases, vol. 180, no. 5, pp. 1429-1435, 1999.
[100] A. Mathew, I. Kurane, S. Green et al., "Impaired T cell proliferation in acute dengue infection," Journal of Immunology, vol. 162, no. 9, pp. 5609-5615, 1999.

[101] K. S. Myint, T. P. Endy, D. Mongkolsirichaikul et al., "Cellular immune activation in children with acute dengue virus infections is modulated by apoptosis," Journal of Infectious Diseases, vol. 194, no. 5, pp. 600-607, 2006.

[102] T. Duangchinda, W. Dejnirattisai, S. Vasanawathana et al., "Immunodominant T-cell responses to dengue virus NS3 are associated with DHF," Proceedings of the National Academy of Sciences of the United States of America, vol. 107, no. 39, pp. 16922-16927, 2010.

[103] R. Appanna, L. H. Tan, L. L. C. See, L. T. Phoay, J. Vadivelu, and S. Devi, "Cross-reactive T-cell responses to the nonstructural regions of dengue viruses among dengue fever and dengue hemorrhagic fever patients in Malaysia," Clinical and Vaccine Immunology, vol. 14, no. 8, pp. 969-977, 2007.

[104] I. Zivna, S. Green, D. W. Vaughn et al., "T cell responses to an HLA-B ${ }^{*} 07$-restricted epitope on the dengue NS3 protein correlate with disease severity," Journal of Immunology, vol. 168, no. 11, pp. 5959-5965, 2002.

[105] T. Kadhiravan, A. Saxena, A. Singh, S. Broor, S. K. Sharma, and D. K. Mitra, "Association of Intracellular $\mathrm{T}_{\mathrm{H}} 1-\mathrm{T}_{\mathrm{H}} 2$ Balance in $\mathrm{CD} 4^{+} \mathrm{T}$-cells and MIP- $1 \alpha$ in CD $8^{+} \mathrm{T}$-cells with disease severity in adults with Dengue," Immune Network, vol. 10, no. 5, pp. 164172.

[106] C. Y. Lai, W. Y. Tsai, S. R. Lin et al., "Antibodies to envelope glycoprotein of dengue virus during the natural course of infection are predominantly cross-reactive and recognize epitopes containing highly conserved residues at the fusion loop of domain II," Journal of Virology, vol. 82, no. 13, pp. 6631-6643, 2008.

[107] C. P. Simmons, T. Dong, N. V. Chau et al., "Early T-cell responses to dengue virus epitopes in Vietnamese adults with secondary dengue virus infections," Journal of Virology, vol. 79, no. 9, pp. 5665-5675, 2005.

[108] M. M. Mangada, T. P. Endy, A. Nisalak et al., "Denguespecific $\mathrm{T}$ cell responses in peripheral blood mononuclear cells obtained prior to secondary dengue virus infections in Thai schoolchildren," Journal of Infectious Diseases, vol. 185, no. 12, pp. 1697-1703, 2002.

[109] S. Hatch, T. P. Endy, S. Thomas et al., "Intracellular cytokine production by dengue virus-specific $\mathrm{T}$ cells correlates with subclinical secondary infection," Journal of Infectious Diseases, vol. 203, no. 9, pp. 1282-1291, 2011. 


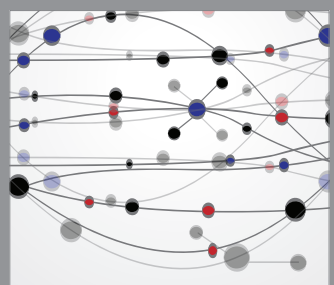

The Scientific World Journal
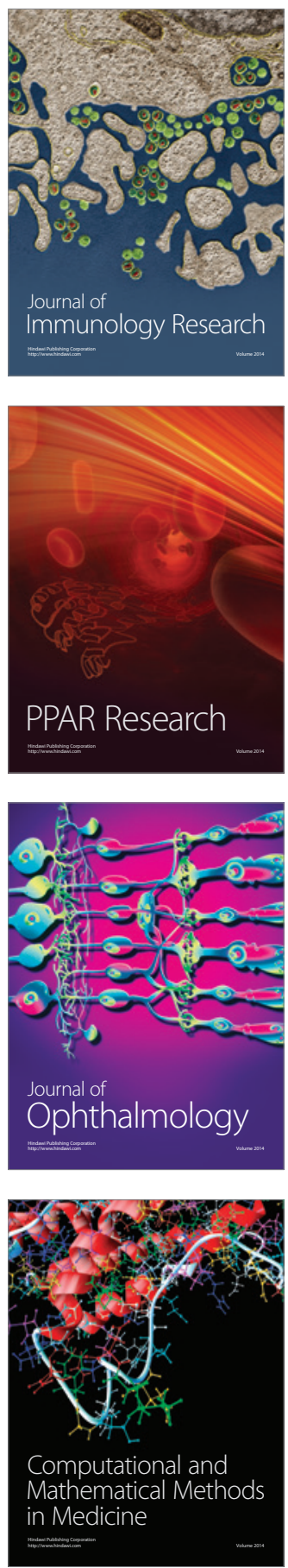

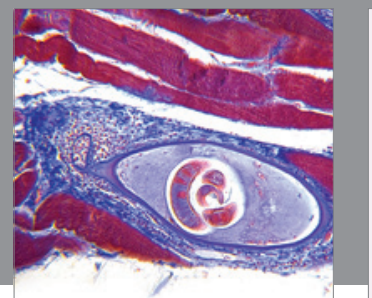

Gastroenterology

Research and Practice
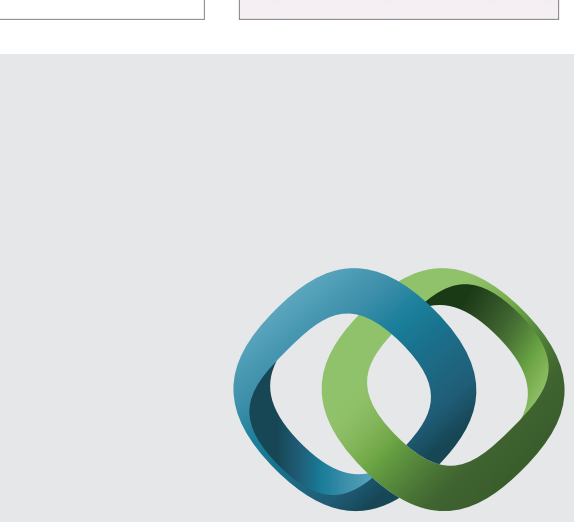

\section{Hindawi}

Submit your manuscripts at

http://www.hindawi.com
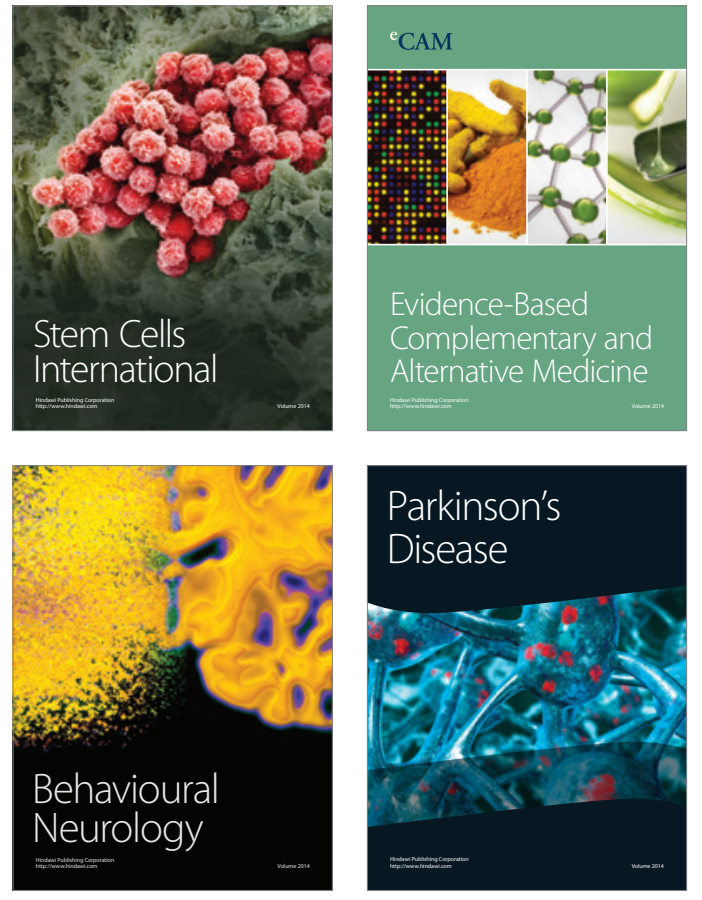
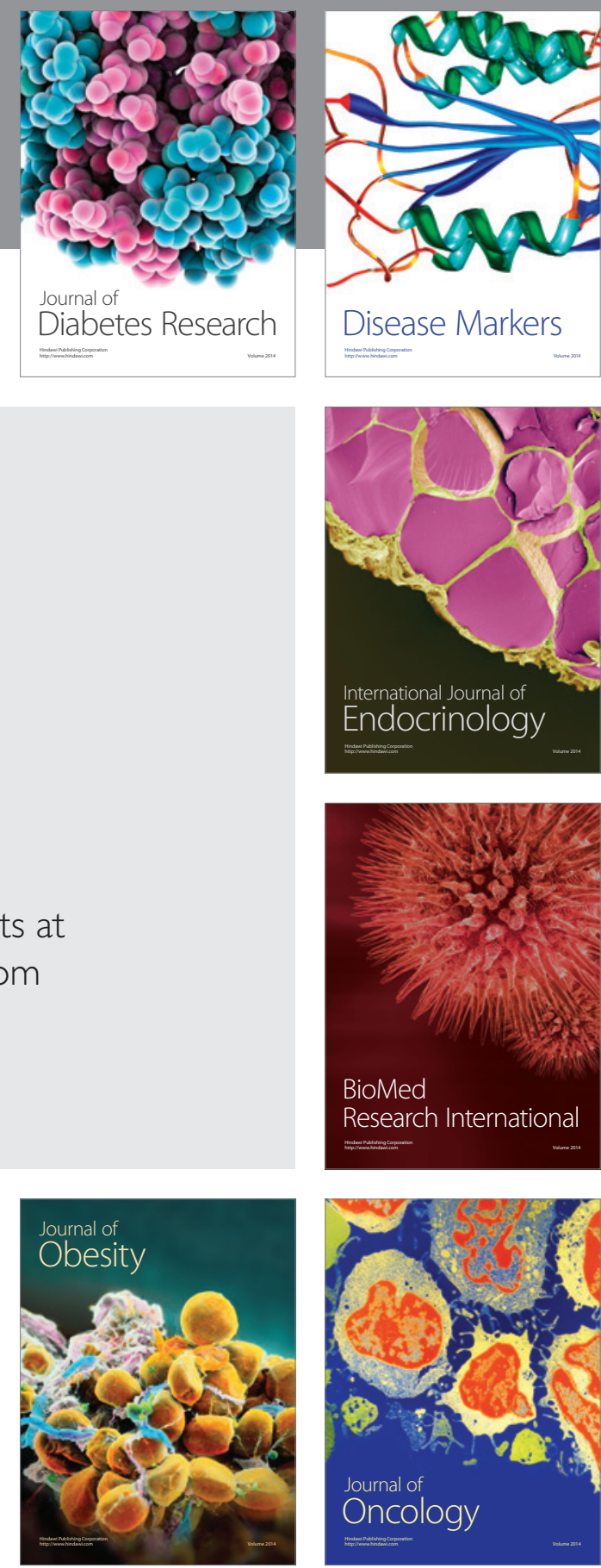

Disease Markers
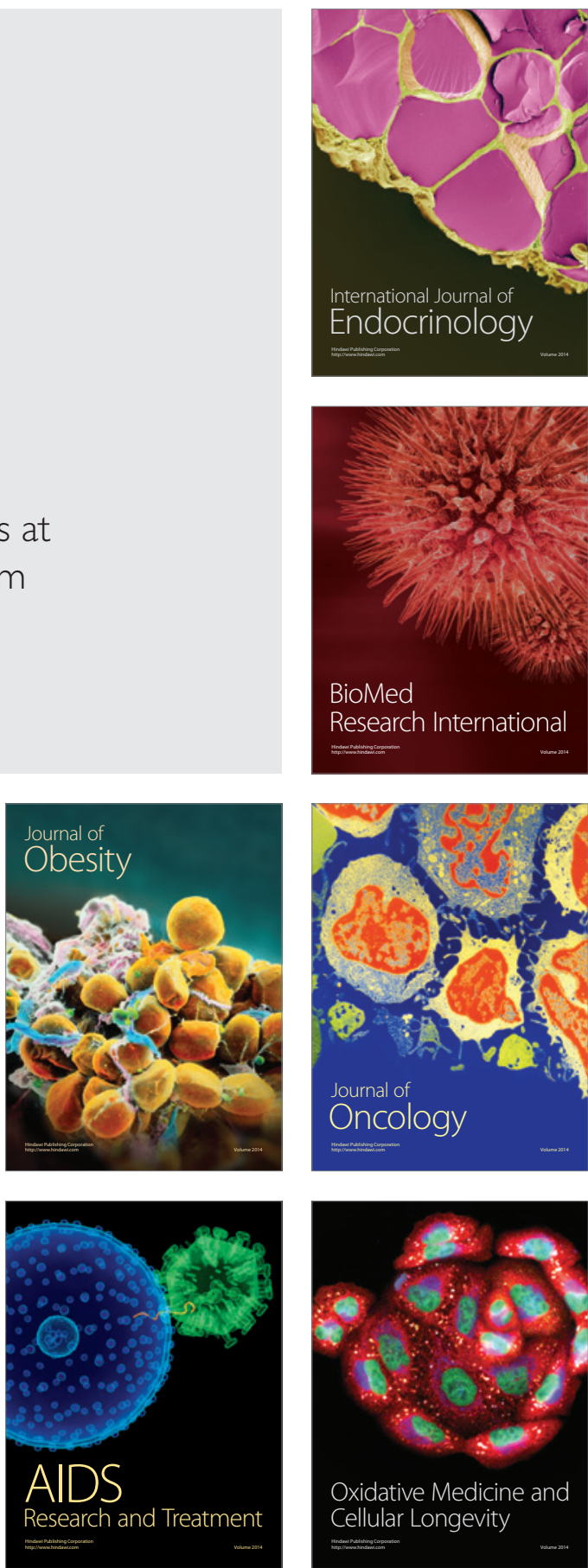